\title{
The Impact of Anti-Corruption on Macau's Gaming Industry: An Externality Analysis
}

\author{
Chaoqun Chen \\ Jinan University, Guangzhou, China \\ Email: 505110909@qq.com
}

How to cite this paper: Chen, C. Q. (2018). The Impact of Anti-Corruption on Macau's Gaming Industry: An Externality Analysis. Chinese Studies, 7, 144-154.

https://doi.org/10.4236/chnstd.2018.72012

Received: January 27, 2018

Accepted: April 1, 2018

Published: April 4, 2018

Copyright $\odot 2018$ by author and Scientific Research Publishing Inc. This work is licensed under the Creative Commons Attribution International License (CC BY 4.0).

http://creativecommons.org/licenses/by/4.0/

\begin{abstract}
This study identifies and decomposes the impact of China's central anti-corruption on Macau's gaming industry by examining the quarter revenue data of six gaming companies from 2010 to the third quarter of 2017. The analysis results show that the negative impact of the anti-corruption campaign on the revenue of Macau's gaming industry is lagging behind, and the strengthening of anti-corruption efforts since the establishment of the 18th Central Committee of the Communist Party of China has caused clear externality. The effect remains significant after excluding the influences of macroeconomic factors, the Brazilian World Cup, and the Asia gaming industry competition. For the impact mechanism, the effect is mainly determined through the per capita gaming of Macau visitors instead of the number of gamers. This study provides empirical support for research on the externality of anti-corruption.
\end{abstract}

\section{Keywords}

Anti-Corruption, Macau, Gaming Industry

\section{Introduction}

With the continuous improvement of mainland China's overall strength and deepening exchanges amongst regional economies, the anti-corruption within has deepened its influence on the surrounding economy through several channels. We find that analyzing the impact of the central anti-corruption on Macau's gaming industry can provide empirical support for anti-corruption externality research.

As the gaming industry is one of the economic pillars of Macau, this country has become one of the largest casino hubs in the world since its gaming rights were liberalized in 2002. As Macau is adjacent to mainland China, tourists from 
the mainland have become an important part of Macau's tourism industry and high-income Chinese are also major gamers ${ }^{1}$. When the central government promotes anti-corruption efforts, the relative number of gamers from mainland China decreases due to censorship or deterrent effect. This condition influences Macau's gaming revenue.

The anti-corruption in the mainland has been strengthened since 2014, causing a decline in the gross gaming revenue of Macau's gaming industry. Li Gang, director of the Macau Joint Liaison Office, said that with the intensification of anti-corruption in mainland China, several corrupt officials, including the leaders of some state-owned enterprises, do not dare to gamble in Macau². Statistics show that in the second, third and fourth quarters of 2014, the revenue of luxury lounges, which account for more than $70 \%$ of Macau's gaming industry, dropped $6 \%, 19 \%$ and $29 \%$, respectively, over the previous year's figures. ${ }^{3}$

What is the effect of the central anti-corruption on Macau's gaming industry? How does this externality happen? Are the externalities significant since the establishment of the Communist Party of China's 18th National Congress? The present study aims to answer these questions based on data obtained from six gaming companies in Macau from 2010 to the third quarter of 2017.

\section{Literature Review}

Regarding the economic impact of corruption and anti-corruption, although some scholars believe that corruption has a positive effect on the economy (Leff, 1964; Huntington, 1969; Rock \& Bonnett, 2004; Aidt et al., 2008; Meon \& Weill, 2008; Wu \& Rui, 2010) anti-corruption have a unified basis on popular opinion. At different stages of economic development, the strength of anti-corruption vary (He, 2000; Elizabeth, 2007) and their impacts on macroeconomics and firm performance vary as well (Murphy et al., 1993; Mauro, 1995; Zeume, 2012).

In China's current environment, the anti-corruption drive is undoubtedly the most closely observed issue, especially since the establishment of the Communist Party's 18th National Congress. Relevant articles include those by Dang et al. (2015), Wang \& Wang (2016) and Ying et al. (2016), who found that anti-corruption is conducive to economic growth at macro and micro levels, and the short-term performance of enterprises seeking political rent is declining. Simultaneously, enterprises improve their performance by optimizing investment efficiency. In addition, the luxury spending of government officials drop significantly.

The central anti-corruption campaign only targets relevant individuals within the mainland but affects other areas, such as Macau, through these individuals'

${ }^{1}$ Statistics from the Macau Bureau of Statistics show that the proportion of mainland tourists has exceeded $60 \%$ since 2012 .

${ }^{2}$ For details, please refer to http://finance.ifeng.com/a/20150311/13547327_0.shtml.

${ }^{3}$ Data source: Macau Gaming Inspection and Coordination Bureau. 
specific behaviours. Macau has a small economy and a single industrial structure, which is significantly affected by external shocks (Zuo et al., 2008; Mao, 2009). The gaming industry is an economic pillar of Macau. Given Macau's proximity to mainland China, many Chinese tourists have become an important factor in developing the island's gaming industry (Du, 2007; Guo \& Zhao, 2009). Therefore, the central anti-corruption campaign of the Chinese government may potentially generate externalities to Macau's economy by reducing the gaming activities of certain groups of people. The present study quantifies the anti-corruption activities in mainland China and analyses its effect on Macau's gaming industry by providing an example of the externality of the anti-corruption.

\section{Empirical Analysis}

Based on the preceding basic understanding and inference, we identify the externalities of the anti-corruption campaign and analyze its mechanism and dynamic changes.

\subsection{Data Description}

Our empirical evidence is based on quarterly data from six gaming companies in Macau from 2010 to the third quarter of 2017. The data sources are the quarterly financial reports of these companies. TR represents the gaming company's revenue, and we use log (TR) as the explanatory variable, which is the natural logarithm of the gaming company's revenue. The core explanatory variables comprise two variables that reflect the anti-corruption drive's intensity: 1) Drop represents the number of officials' drops in quarters compiled through the website of the Central Commission for Discipline Inspection and the anti-corruption official website, including the following three categories of officers: (a) central management cadres; (b) cadres of central-level party and state organs, state-owned enterprises, and financial units; and (c) provincial cadres; 2) CP represents the quarterly patrol units of the central inspection group after the opening of the 18th CPC National Congress; these units are collected from the central inspection work site.

In the control variables, SP500 represents the S \& P 500 index $^{4}$; TGT represents the total number of quarterly travelers to Macau worldwide ${ }^{5}$; OGT represents the total number of annual travelers to Macau for the rest of the world except mainland China; JC represents the sales of quarterly quasi-type lottery of the mainland ${ }^{6}$; Casino_1 represents the quarterly increase in the number of casinos in Asia except $\mathrm{Macau}^{7}$; and Casino_2 represents the accumulative quarterly increase of casinos in Asia except Macau. We add the aforementioned control variables to control the impact of other macroeconomic factors on $\mathrm{Ma}$ -

${ }^{4}$ Data source: http://finance.yahoo.com/.

${ }^{5}$ Data source: Macau Bureau of Statistics.

${ }^{6}$ Data source: http://zhs.mof.gov.cn/zhengwuxinxi/zonghexinxi/.

${ }^{7}$ Data source: https://www.worldcasinodirectory.com/worldcasinos.htm. 
cau's gaming industry.

In the mechanism analysis, AGT and GDP rate represent the quarterly GGR and quarter-on-quarter YOY growth of GDP per capita in 23 provinces of mainland China and 21 other countries, respectively. ${ }^{8}$ Specific statistical description is provided in Table 1.

\subsection{Basic Identification}

This study uses Equation (1) to identify the impact of central anti-corruption on the quarterly gaming revenue of Macau's six gaming firms.

$$
\log (\mathrm{TR})_{i t}=c+\beta A C_{t}+\alpha_{i}+\theta_{t}^{\text {Year }}+\theta_{t}^{\text {Quarter }}+\varepsilon_{i t} .
$$

In Equation (1), the explained variable $\log (\mathrm{TR})_{i t}$ represents the logarithm of the gaming company's revenue $i$ at time $t$, the core explanatory variable vector is the measure of anti-corruption intensity, AC, and we will construct it from Drop and CP. $\alpha_{i}$ reflects the gaming companies individual firmness and is used to control the individual heterogeneity of the gaming company; $\theta^{\text {Year }}$ and $\theta^{\text {Quarter }}$ are the fixed effects of the year and the fixed effects of the quarter and are used to control the revenue growth's impact of Macau gaming company over time (the development of new projects, the expanding of the scale); $\varepsilon_{i t}$ represent the random error term.

Table 2 presents basic identification results. In columns (1) and (2), we examine the effect of officials' drops on the current and delayed phases of gaming revenue in Macau. Results show that the anti-corruption campaign has a significant lag effect on Macau's gaming industry. Thus, we initially assume that negative externalities exist. As CP indicates the quarterly inspection units' number of

Table 1. Descriptive statistics of major variables.

\begin{tabular}{cccccc}
\hline Variable & Mean & Standard deviation & Minimum & Maximum & Observations \\
\hline TR & 1338.785 & 659.3806 & 313.386 & 3160.215 & 186 \\
Drop & 45.581 & 47.590 & 0 & 144.000 & 31 \\
CP & 13.129 & 14.294 & 0 & 42.000 & 31 \\
SP500 & 1717.591 & 416.334 & 1096.247 & 2467.175 & 31 \\
TGT & 596.200 & 100.454 & 248.122 & 814.605 & 31 \\
OGT & 433.478 & 86.467 & 196.329 & 687.875 & 31 \\
JC & 116.713 & 65.493 & 21.460 & 249.830 & 31 \\
Casino_1 & 1.000 & 1.183 & 0 & 4 & 31 \\
Casino_2 & 12.129 & 9.851 & 2 & 31 & 31 \\
AGT & 12.611 & 58.559 & 0 & 493.985 & 1144 \\
GDPrate & 0.066 & 0.099 & -0.750 & 0.365 & 1144 \\
\hline
\end{tabular}

Note: Results are obtained using Stata 13.1.

${ }^{8}$ Mainland China's GDP data are collected from the DRCNET Statistical Database System while the other 21 countries' (regions) GDP data are collected from EIU Country data. 
Table 2. Basic identification of impact of central anti-corruption campaign on Macau's gaming industry.

\begin{tabular}{ccccc}
\hline & \multicolumn{4}{c}{$\log (\mathrm{TR})$} \\
\cline { 2 - 5 } & $(1)$ & $(2)$ & $(3)$ & $(4)$ \\
\hline Drop & 0.015 & & & \\
Drop (-1) & $(0.037)$ & & & \\
& & $-0.224^{* * *}$ & $-0.205^{* * *}$ & $-0.154^{* * *}$ \\
Drop (-1).CP & & $(0.033)$ & $(0.033)$ & $(0.020)$ \\
& & & $-0.002^{*}$ & \\
Drop (-1).CP (-1) & & & $(0.001)$ & \\
Annual fixed effect & Control & Control & Control & Control \\
Quarterly fixed effect & Control & Control & Control & Control \\
Individual fixed effect & Control & Control & Control & Control \\
Constant term & $6.627^{* * *}$ & $6.662^{* * *}$ & $6.665^{* * *}$ & $6.642^{* * *}$ \\
& $(0.141)$ & $(0.154)$ & $(0.155)$ & $(0.157)$ \\
Observations & 186 & 180 & 180 & 180 \\
R2 & 0.543 & 0.521 & 0.522 & 0.525 \\
\hline
\end{tabular}

Note: Robust standard errors in parentheses. ${ }^{*},{ }^{* *},{ }^{* *}$ indicate the significance at $10 \%, 5 \%, 1 \%$ levels, respectively. Results are obtained using Stata 13.1.

the Central Inspection Group after the 18th National Congress, in the regression of columns (3) and (4), we add the cross-multiplying terms of Drop and CP to measure the dynamic change of this externality since the establishment of the 18th National Congress. Results show that the cross-multiplying terms of L. Drop and L.CP is significant at $1 \%$ level, which indicates that after the 18th CPC National Congress, strengthening the central anti-corruption has intensified the externalities. Accordingly, we test the robustness in the next section.

\subsection{Robustness Test}

From the previous section, we identify the anti-corruption campaign's negative externalities against Macau's gaming industry. Based on this preliminary conclusion, we conduct a series of robustness tests to enhance the credibility of conclusions. Based on regression Equation (1), other control variables are added to isolate the effects of other factors that may exist.

1) Robustness test based on macroeconomic environment

Macau is vulnerable to fluctuations of the external economic environment because of its small economy with a single industrial structure. Therefore, we must confirm whether or not the externalities of anti-corruption remain significant after weeding out these impacts. Specifically, we add the S \& P 500 to reflect macroeconomic volatility. In addition, as foreign tourists dominate Macau's 
gaming industry, macroeconomic fluctuations affect this industry through changes in the number of gaming tourists. Accordingly, we also consider the number of Macau's gaming tourists as an alternative measure of the macroeconomic situation, including TGT and OGT. Results are shown in columns (1) to (6) of Table 3. We find that after controlling for such variables, the coefficients for anti-corruption variables remain significantly negative at $1 \%$ level. Therefore, the robustness of the conclusions has been raised.

2) Robustness test based on incident factor

In addition, we expect that the externalities from results are not from the effects of other incidents. The Brazil World Cup held in mid-2014 has caused the rapid growth of the lottery in mainland China. From a practical point of view, the quasi-type lottery has the nature of gaming. In view of the large dependence of the gaming industry on mainland China's market and the overlapping of the anti-corruption campaign and the Brazil World Cup, we must test whether or not the impact of anti-corruption on Macau's gaming industry remains significant after excluding the growth in sales' impact on quasi-type lottery. Columns (1) to (6) in Table 4 show that the coefficient of L. Drop remains significantly negative after controlling for Mainland China's quasi-type lottery sales (JC). In addition, the cross-multiplying terms of L. Drop and L.CP's coefficient remains significantly negative; thus, the validity of the basic conclusion we preliminarily proposed is supported.

Table 3. Robustness test based on macroeconomic environment.

\begin{tabular}{|c|c|c|c|c|c|c|}
\hline & \multicolumn{6}{|c|}{$\log (\mathrm{TR})$} \\
\hline & (1) & (2) & (3) & (4) & (5) & (6) \\
\hline \multirow[t]{2}{*}{ Drop $(-1)$} & $-0.243^{\star * *}$ & $-0.223^{* * *}$ & $-0.227^{\star \star \star}$ & $-0.171^{\star \star}$ & $-0.158^{* * *}$ & $-0.160^{\star * *}$ \\
\hline & $(0.025)$ & $(0.033)$ & $(0.033)$ & $(0.048)$ & $(0.020)$ & $(0.020)$ \\
\hline \multirow{2}{*}{ Drop $(-1) \cdot \mathrm{CP}(-1)$} & & & & $-0.005^{*}$ & $-0.005^{\star * *}$ & $-0.005^{\star * *}$ \\
\hline & & & & $(0.002)$ & $(0.001)$ & $(0.001)$ \\
\hline SP500 & Control & & & Control & & \\
\hline TGT & & Control & & & Control & \\
\hline OGT & & & Control & & & Control \\
\hline Annual fixed effect & Control & Control & Control & Control & Control & Control \\
\hline Quarterly fixed effect & Control & Control & Control & Control & Control & Control \\
\hline $\begin{array}{c}\text { Individual fixed } \\
\text { effect }\end{array}$ & Control & Control & Control & Control & Control & Control \\
\hline \multirow[t]{2}{*}{ Constant term } & $6.469^{* * *}$ & $6.745^{* * *}$ & $6.782^{* * *}$ & $6.529^{* * *}$ & $6.682^{* * *}$ & $6.741^{* * *}$ \\
\hline & $(0.244)$ & $(0.158)$ & $(0.173)$ & $(0.272)$ & $(0.170)$ & $(0.180)$ \\
\hline Observations & 180 & 180 & 180 & 180 & 180 & 180 \\
\hline R2 & 0.522 & 0.522 & 0.523 & 0.525 & 0.525 & 0.526 \\
\hline
\end{tabular}

Note: Robust standard errors in parentheses. ${ }^{\star},{ }^{* *},{ }^{* *}$ indicate significance at $10 \%, 5 \%, 1 \%$ levels, respectively. Results are obtained using Stata 13.1. 
Table 4. Robustness test based on incident factors.

\begin{tabular}{ccccccc}
\hline & \multicolumn{5}{c}{ Log (TR) } \\
\cline { 2 - 7 } & $(1)$ & $(2)$ & $(3)$ & $(4)$ & $(5)$ & $(6)$ \\
\hline Drop (-1) & $-0.265^{* * *}$ & $-0.248^{* * *}$ & $-0.250^{* * *}$ & $-0.183^{* *}$ & $-0.173^{* * *}$ & $-0.170^{* * *}$ \\
& $(0.035)$ & $(0.039)$ & $(0.039)$ & $(0.053)$ & $(0.034)$ & $(0.033)$ \\
Drop (-1).CP (-1) & & & & $-0.004^{*}$ & $-0.004^{* *}$ & $-0.004^{* *}$ \\
& & & & $(0.002)$ & $(0.001)$ & $(0.001)$ \\
SP500 & Control & & & Control & & \\
TGT & & Control & & & Control & \\
OGT & & & Control & & & Control \\
Annual fixed effect & Control & Control & Control & Control & Control & Control \\
Quarterly fixed effect & Control & Control & Control & Control & Control & Control \\
Individual fixed \\
effect & Control & Control & Control & Control & Control & Control \\
Constant term & $6.503^{* * *}$ & $6.712^{* * *}$ & $6.751^{* * *}$ & $6.541^{* * *}$ & $6.670^{* * *}$ & $6.733^{* * *}$ \\
& $(0.258)$ & $(0.144)$ & $(0.161)$ & $(0.277)$ & $(0.156)$ & $(0.166)$ \\
Observations & 180 & 180 & 180 & 180 & 180 & 180 \\
R2 & 0.523 & 0.523 & 0.523 & 0.525 & 0.525 & 0.526 \\
\hline
\end{tabular}

Note: Robust standard errors in parentheses. ${ }^{*},{ }^{* *},{ }^{* *}$ indicate significance at $10 \%, 5 \%, 1 \%$ levels, respectively. Results are obtained using Stata 13.1.

3) Robustness test based on Asia gaming competition

With the casino market's rapid expansion in Asia, the casino competition in Asia has become fierce in recent years. Many Asian countries, such as Singapore, the Philippines and Vietnam, have newly established or expanded their casinos and are looking forward to the role of the gambling industry in revitalizing tourism by attracting tourists from around the world, while large casino resorts are previously operated mainly by United States and Macau businesses. Until the third quarter of 2017, 275 casinos operated in 18 Asian countries except Macau and a number of casinos are expected to open for business from 2018 to $2020^{9}$. As the growing number of casinos in Asia in recent years will likely distract gaming travelers and thus affect the gaming revenue in Macau, we have to test whether or not the externalities shown in the basic regression results will remain significant after the competition's effects are eliminated, to confirm the externalities of corruption.

Columns (1) to (4) in Table 5 indicate that after controlling Casino_1 and Casino_2 in the other Asian countries, the coefficient of L. Drop remains significantly negative, and the coefficient of the cross-multiplying terms of L. Drop and L.CP also remains significantly negative; thus, our preliminary basic conclusion is strengthened. Specifically, anti-corruption has negative externality to ${ }^{9}$ Data source: https://www.worldcasinodirectory.com/worldcasinos.htm. 
Table 5. Robustness test based on Asia gaming competition.

\begin{tabular}{ccccc}
\hline & \multicolumn{4}{c}{ Log (TR) } \\
\cline { 2 - 5 } & $(1)$ & $(2)$ & $(3)$ & $(4)$ \\
\hline Drop (-1) & $-0.026^{* * *}$ & $-0.031^{* * *}$ & $-0.017^{* * *}$ & $-0.026^{* * *}$ \\
& $(0.003)$ & $(0.004)$ & $(0.002)$ & $(0.002)$ \\
Drop (-1).CP (-1) & & & $-0.001^{* * *}$ & $-0.000^{* *}$ \\
Casino_1 & Control & & $(0.000)$ & $(0.000)$ \\
Casino_2 & & Control & \\
Annual fixed effect & Control & Control & Control & Control \\
Quarterly fixed effect & Control & Control & Control & Control \\
Individual fixed effect & Control & Control & Control & Control \\
Constant term & $6.682^{* * *}$ & $6.676^{* * *}$ & $6.661^{* * *}$ & $6.661^{* * *}$ \\
& $(0.160)$ & $(0.153)$ & $(0.161)$ & $(0.157)$ \\
Observations & 180 & 180 & 180 & 180 \\
R2 & 0.525 & 0.536 & 0.533 & 0.537 \\
\hline
\end{tabular}

Note: Robust standard errors in parentheses. ${ }^{*},{ }^{* *},{ }^{* *}$ indicate significance at $10 \%, 5 \%, 1 \%$ levels, respectively. Results are obtained using Stata 13.1.

Macau's gaming industry, and the externality has been further enhanced after the establishment of the 18th CPC National Congress.

\subsection{Mechanism Analysis of Externality}

From the previous section, we identify and test the impact of the anti-corruption campaign on Macau's gaming industry. Moreover, we aim to determine the mechanism of this externality. Speculating that the impact on Macau's gaming industry can be easily achieved in two ways: 1) by influencing the number of gaming travelers visiting Macau and 2) by influencing the per-capita gaming spending of Macau gaming travelers. We aim to judge the path through which anti-corruption works to influence Macau's gaming industry. We proceed based on Equation (2):

$$
\log (\mathrm{AGT})_{i t}=c+\beta A C_{t}+\alpha_{i}+\theta_{t}^{\text {Year }}+\theta_{t}^{\text {Quarter }}+\gamma Z_{t}+\varepsilon_{i t}
$$

Equation (2) analyses whether or not the anti-corruption has significantly affected the number of mainland gaming travelers visiting Macau. Amongst them, $\mathrm{AGT}_{i t}$ represents the number of gamblers travelling to Macau from province (country/region) $i$ at time $t$, as the rest of the countries (regions) except the provinces in mainland China are unaffected by the central anti-corruption campaign, the Drop values corresponding to the samples of these countries are $0 ; z$ is a control variable; and we use GDP rate to control the effect of the year-on-year growth rate difference of provinces (countries/regions). $\alpha_{i}$ is a province (country) fixed effect that controls the provinces' (countries') difference due to fixed factors, such as geographic distance and cultural differences. The remain- 
ing variables are similar in regression (1). Results are shown in Table 6. In columns (1) and (2), we examine the coefficient of L. According to Drop in column (1), the coefficient is significantly negative, which means that the anti-corruption drive significantly reduced the number of mainland gaming travelers visiting Macau. That is, the anti-corruption externality mainly works through the decline in the number of gaming players. However, the result shows that its coefficient is significantly positive, indicating that the anti-corruption campaign does not significantly reduce the number of gaming travelers visiting Macau.

Similarly, given the situation after the 18th National Congress of the Communist Party of China, the coefficient of the cross-multiplying terms of L. Drop and L. CP also remains significantly positive at the $1 \%$ level. Therefore, the anti-corruption and the intensified anti-corruption efforts after the 18th National Congress do not significantly reduce the number of gaming travellers visiting Macau. Thus, we can judge that the mechanism of anti-corruption externality works through the decline of per-capita gaming spending. By combining background knowledge with our findings, we can assume that a small number of people (such as luxury guests) who invest heavily in gaming has reduced their overall per-capita gaming spending, which is related to the corruption deterrent.

\section{Conclusion}

Based on the externalities of the anti-corruption campaign, the central anti-corruption has had an impact on neighboring economies. Given its geographical proximity to mainland China and unique industrial characteristics,

Table 6. Mechanism Analysis.

\begin{tabular}{ccc}
\hline & \multicolumn{2}{c}{ Log (AGT) } \\
\cline { 2 - 3 } & $(1)$ & $(2)$ \\
\hline Drop $(-1)$ & $0.053^{* * *}$ & $-0.022^{*}$ \\
Drop $(-1) \cdot \mathrm{CP}(-1)$ & $(0.009)$ & $(0.013)$ \\
& & $0.004^{* * *}$ \\
GDP rate & & $(0.001)$ \\
Annual fixed effect & Control & Control \\
Quarterly fixed effect & Control & Control \\
Individual fixed effects & Control & Control \\
Constant term & Control & Control \\
& $0.182^{* * *}$ & $0.184^{* * *}$ \\
Observations & $(0.065)$ & $(0.065)$ \\
R2 & 1100 & 1100 \\
\hline
\end{tabular}

Note: Robust standard errors in parentheses. ${ }^{*},{ }^{* *},{ }^{* *}$ indicate significance at $10 \%, 5 \%, 1 \%$ levels, respectively. Results are obtained using Stata 13.1. 
Macau has become one of the main recipients of the central anti-corruption influence on externalities. Taking the anti-corruption work by the central government as an example since 2010, the present study uses the quarterly revenue data acquired from six gaming companies in Macau from 2010 to the third quarter of 2017 to identify the anti-corruption's impact on Macau's gaming industry and analyze its dynamics and approaches.

Research shows that the central anti-corruption has a negative external effect on Macau's gaming industry. The impact has one lag, and the externalities have become apparent since the establishment of the 18th CPC National Congress. After excluding the influences of macroeconomic factors, the Brazilian World Cup and the Asia gaming industry competition, the conclusion is robust. For the influence, this externality is mainly due to the effect of Macau's per-capita gaming spending. Combining these results with the basic facts, we can conclude that the anti-corruption leads to a reduction in high-spending groups involved in betting, which drags down the overall per-capita gaming spending. We propose that a connection exists between these high-consumption groups and the corruption deterrent. This study has raised an awareness of the anti-corruption's impact and provided an example of its externality.

\section{References}

Aidt, T., Dutta, J., \& Sena, V. (2008). Governance Regimes, Corruption and Growth: Theory and Evidence. Journal of Comparative Economics, 36, 195-220. https://doi.org/10.1016/j.jce.2007.11.004

Ayyagari, M., Demirgüç-Kunt, A., \& Maksimovic, V. (2014). Bribe Payments and Innovation in Developing Countries: Are Innovating Firms Disproportionately Affected? Journal of Financial \& Quantitative Analysis, 49, 51-75. https://doi.org/10.1017/S002210901400026X

Dang, L., Yang, R. L., \& Yang, J. D. (2015). Anti-Corruption and Business Innovation: An Explanation Based on Political Connections. China Industrial Economics, 7, 146-160.

Du, X. (2007). Exploring Human Resource Challenges in the Casino Industry. Journal of Macau Gaming Research Association, 4, 24-30.

Quade, E. A. (2007). The Logic of Anticorruption Enforcement Campaigns in Contemporary China. Journal of Contemporary China, 16, 65-77. https://doi.org/10.1080/10670560601026751

Guo, X. D., \& Liu, C. S. (2009). Macau's Gambling Industry's Economic Driving Capability and Its Industrial Policy Orientation. International Economic and Trade Exploration, 8, 21-26.

He, Z. (2000). Corruption and Anti-Corruption in Reform China. Communist and Post-Communist Studies, 33, 243-270. https://doi.org/10.1016/S0967-067X(00)00006-4

Huntington, S. P. (1969). Political Order in Changing Societies. Midwest Journal of Political Science, 13, 495-496. https://doi.org/10.2307/2110237

Leff, N. H. (1964). Economic Development through Bureaucratic Corruption. American Behavioral Scientist, 8, 8-14. https://doi.org/10.1177/000276426400800303

Mao, Y. H. (2009). Macau Moderate Economic Diversification: Connotation, Path and Policy. Sun Yat-sen University (Social Science Edition), 5, 149-157. 
Mauro, P. (1995). Corruption and Growth. Quarterly Journal of Economics, 110, 681-712. https://doi.org/10.2307/2946696

Meon, P. G., \& Weill, L. (2008). Is Corruption an Efficient Grease? World Development, 38, 244-259. https://doi.org/10.1016/j.worlddev.2009.06.004

Murphy, K. M., Shleifer, A., \& Vishny, R. W. (1993). Why Is Rent-Seeking So Costly to Growth? American Economic Review, 83, 409-414.

Rock, M. T., \& Bonnett, H. (2004). The Comparative Politics of Corruption: Accounting for the East Asian Paradox in Empirical Studies of Corruption, Growth and Investment. World Development, 32, 999-1017. https://doi.org/10.1016/j.worlddev.2003.12.002

Wang, X. B., \& Wang, L. Y. (2016). Anti-Corruption and Economic Growth. Comparison of Economic and Social Systems, 2, 61-74.

Wu, Y. P., \& Rui, M. (2010). Regional Corruption, Marketization and China's Economic Growth. Management World, 11, 10-17.

Ying, Q. W., Liu, J. S., \& Zhang, Y. (2016). Corruption and Corporate Value-Evidence from the Anti-Corruption Era after the 18th National Congress of the CCP. World Economic Articles, 3, 42-63.

Zuo, L. C., Xu, J. X., \& Cai, S. (2008). Some Thoughts on the Development of Macau Gaming Industry. Economic Front, 21, 49-53. 